\title{
Bacteriological Profile of Neonatal Sepsis in a Tertiary Level Hospital of Nepal
}

\author{
Khanal $\mathbf{R}^{1}$, Manandhar $\mathrm{S}^{2}$, Acharya $\mathrm{GP}^{3}$
}

\begin{abstract}
Introduction: Neonatal sepsis is one of the most common reasons for admission to neonatal units in developing countries. It is also a major cause of mortality in both developed and developing countries. This study was done to determine the bacterial profile causing neonatal sepsis and to assess their susceptibility pattern to various antimicrobial agents. Materials and Methods: A cross-sectional prospective study was conducted in Paropakar Maternity and Women's Hospital, Kathmandu, Nepal among 340 neonates suspected of neonatal sepsis. Blood culture was performed and organisms were identified with Gram staining and conventional biochemical methods. Antimicrobial susceptibility testing was performed by Kirby-Bauer disk diffusion method according to the Clinical and Laboratory Standards Institute (CLSI). Results: The prevalence rate of neonatal sepsis was $20.3 \%$. Among 340 neonates, $52.17 \%$ were males and $47.82 \%$ were females. Gram positive cocci were the most predominant isolates (88.40\%). Among Gram positive cocci Staphylococcus epidermidis was the most common isolates $(72.46 \%)$ followed by Staphylococcus aureus $(7.24 \%)$, Staphylococcus saprophyticus (4.34\%) and Enterococcus fecalis (4.34\%). Gram negative bacilli were found in $11.60 \%$ of the growth positive samples of which E.coli and Klebsiella spp were found in $10.14 \%$ and $1.44 \%$ respectively. Sensitivity to Amikacin was highest among all types of organisms isolated. Vancomycin and Gentamycin sensitivity was highest for Gram positive and Gram negative organisms respectively. Ampicillin resistance was highest among isolates. Among the 69 isolates 48 were Multiple drug resistant. Conclusion: The predominance of Gram positive cocci particularly Coagulase negative Staphylococci is shown. Empirical antibiotic therapy should be reviewed for Multiple drug resistant strains.
\end{abstract}

Key words: Neonatal sepsis, Early onset sepsis, Late onset sepsis, Multiple drug resistant.

\section{Introduction}

$\mathrm{N}$ eonatal Sepsis (sepsis neonatorum) is a clinical syndrome resulting from the pathophysiologic effects of local or systemic infection in the first month of life. Neonatal sepsis remains as an important cause of morbidity and mortality among infants in
'Rita Khanal, M.Sc. Medical Microbiology, Assistant Professor, Universal College of Medical Sciences, Bhairahawa Nepal, ${ }^{2}$ Sarita Manandhar, M.Sc. Medical Microbiology, Assistant Professor, National College Kathmandu, Nepal. ${ }^{3}$ Ganesh Prasad Acharya, M. Sc. Medical Lab Techonology, Department of Pathology, Paropkar Maternity and Women's Hospital Kathmandu, Nepal.

\author{
Address for correspondence: \\ Ms. Rita Khanal \\ Assistant Professor \\ Department of Microbiology, \\ Universal College of Medical Sciences \\ Bhairahawa Nepal \\ E-mail ritakhanal@gmail.com \\ Telephone No. 009779867188819
}

\section{How to cite}

Khanal R, Manandhar S, Acharya GP. Bacteriological Profile of Neonatal Sepsis in a Tertiary Level Hospital of Nepal. J Nepal Paediatr Soc 2014;34(3):175-180.

doi: http://dx.doi.org/10.3126/jnps.v34i3.9183

This work is licensed under a Creative Commons Attribution 3.0 License.

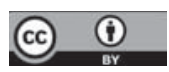

developing countries accounting for $30-50 \%$ of total deaths each year ${ }^{1}$. The incidence of sepsis in neonatal period is 1-10 per 1000 live births with a mortality rate as high as $15-20 \%{ }^{2}$. It is roughly three times more in developing countries like Nepal. This high incidence is mainly due to poor antenatal care and lack of trained staff to conduct deliveries ${ }^{3}$. Classical neonatal infection has been divided into Early or Late onset 
infection, depending on the time of onset of infection: early, before 48 hours and late, after 48 hours ${ }^{4}$.

The common organisms responsible are Group B Streptococcus, Gram negative enteric organisms particularly E.coli, other organisms such as Staphylococcus, Streptococcus, Listeria monocytogens, Haemophilus influenzae, Gram negative rods such as Klebsiella, Pseudomonas, Serratia and Proteus ${ }^{5}$.Since the spectrum of organisms that cause neonatal sepsis changes overtime and varies from region to region and hospital to hospital even in the same city/country, it is necessary to conduct periodic surveillance to access the changing pattern of organisms causing neonatal sepsis. For effective management of neonatal septicemia with appropriate antibiotics, study of bacteriological profile and their antibiotic sensitivity pattern plays a significant role. In our country pre-existing data on both early and late onset sepsis has been shown great diversity in the changing patterns of the organisms and their sensitivity patterns.

Based on this consideration, a study was carried out to investigate the causative bacterial organisms of Neonatal sepsis and to assess their antibiotic susceptibility pattern in the Neonatal unit of Paropakar Maternity and Women's Hospital, Thapathali, Kathmandu, Nepal.

\section{Materials and Methods}

A cross-sectional prospective study was conducted at the Microbiological Laboratory of Paropakar Maternity and Women's Hospital from the period of December 2010 to April 2011. A total of 340 neonates ( 0 to 28 days of age) admitted with suspected cases of early onset sepsis (0-2 days of age, $n=229$ ) and late onset sepsis ( $>3-28$ days of age, $n=71$ ) were investigated. One $\mathrm{ml}$ venous blood was drawn from the antecubital or femoral vein taking aseptic precautions by applying Povidone iodine and $70 \%$ alcohol at the site of vein puncture, and was inoculated into Brain Heart Infusion Broth (HiMedia, India) for culture. The specimens were transported within one hour to the Microbiology Laboratory. All positive blood cultures were identified by their characteristic appearance on their respective media, Gram staining reaction and biochemical reactions. Antimicrobial susceptibility testing was performed by disk diffusion method according to the Clinical and Laboratory Standards Institute $(\mathrm{CLSI})^{6,7}$.

\section{Results}

Out of 340 samples 69 were blood culture positive. The prevalence rate of Neonatal septicemia was found to be $20.3 \%$. Among the total neonates 172 were males and 168 were female. Out of which growth positive cultures of male neonates were 36(52.17\%) and female were $33(47.82 \%)$. There was no significant difference between the sex of the baby and growth of the organism $(p>0.05)$. Among the positive blood culture reports 50 of them were of EOS and 19 were LOS type (Figure 1).

Of 69 growth positive blood cultures, Gram positive cocci were the most predominant isolates (88.40\%). Among gram positive cocci Staphylococcus epidermidis was the most common isolates (72.46\%) followed by Staphylococcus aureus (7.24\%), Staphylococcus saprophyticus (4.34\%) and Enterococcus fecalis (4.34\%). Gram negative bacilli were found in $11.60 \%$ of the growth positive samples of which E.coli and Klebsiella spp were found in $10.14 \%$ and $1.44 \%$ respectively (Table 1 ).

The predominant organism in both Early and Late onset sepsis was S.epidermidis (Table 2). There was no significant difference between the organisms isolated and the onset of Neonatal sepsis ( $p>0.05)$.

The antibiotic sensitivity testing was performed for 69 isolates. The organisms isolated showed different sensitivity to the drugs used. Amikacin showed the highest sensitivity to all types of organisms isolated from the positive blood culture. Vancomycin sensitivity was highest for Gram positive organism and Gentamicin was most effective for Gram negative organisms isolated. Ampicillin was the resistant drug (Table 3).

Among the 69 isolates 48 (69\%) were MDR (Table 4). Of the total MDR, the number of Gram negative MDR was $8(100 \%)$ and Gram positive were 40 (65.57\%).

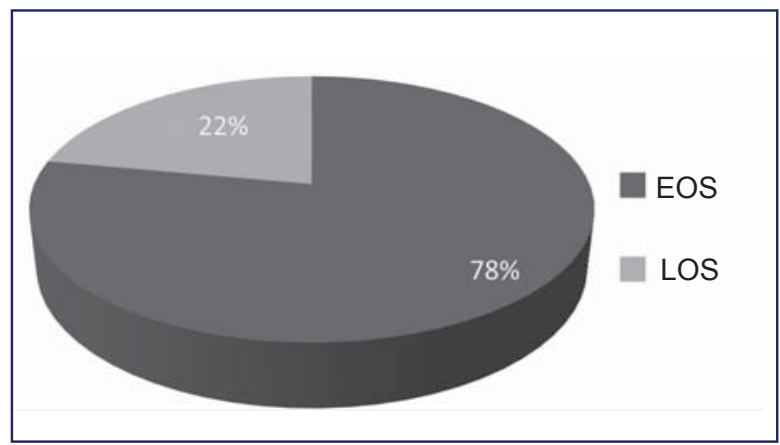

Fig 1: Pie chart showing the distribution of neonatal septicemia based on the onset of disease 
Table 1: Bacteriological profile of the positive blood culture

\begin{tabular}{|c|c|c|}
\hline Organisms & Number & Percentage (\%) \\
\hline \multicolumn{3}{|c|}{ Gram negative } \\
\hline E.coli & 7 & 10.14 \\
\hline Klebsiellaspp & 1 & 1.44 \\
\hline Total & 8 & 11.59 \\
\hline \multicolumn{3}{|c|}{ Gram positive } \\
\hline S. aureus & 5 & 7.24 \\
\hline S. epidermidis & 50 & 72.46 \\
\hline S. saprophyticus & 3 & 4.34 \\
\hline Enterococcus fecalis & 3 & 4.34 \\
\hline Total & 61 & 88.40 \\
\hline
\end{tabular}

Table 2: Bacteriological Profile of the EOS and LOS.

\begin{tabular}{|l|c|c|c|}
\hline Organisms & EOS & LOS & p-value \\
\hline E.coli & $6(12.00 \%)$ & $1(5.26 \%)$ & $0(0.00 \%)$ \\
\hline Klebsiella spp & $1(2.00 \%)$ & $15(78.94 \%)$ & \multirow{2}{*}{$p>0.05$} \\
\hline S.epidermidis & $35(70.00 \%)$ & $2(10.52 \%)$ & \\
\hline S.aureus & $3(6.00 \%)$ & $0(0.00 \%)$ & $1(5.26 \%)$ \\
\hline S.saprophyticus & $3(6.00 \%)$ & 19 & \\
\hline Enterococcus fecalis & $2(4.00 \%)$ & & \\
\hline Total & 50 & & \\
\hline
\end{tabular}

Table 3: Antibiotic Sensitivity Pattern of the Isolated Organisms

\begin{tabular}{|c|c|c|c|c|c|c|c|}
\hline \multirow{2}{*}{\multicolumn{2}{|c|}{ Antibiotics }} & \multicolumn{6}{|c|}{ Organisms } \\
\hline & & \multirow{2}{*}{$\begin{array}{c}\begin{array}{c}\text { E.coli } \\
(n=7)\end{array} \\
4(57.14 \%)\end{array}$} & \multirow{2}{*}{$\begin{array}{c}\text { Klebsiellaspp(n=1) } \\
0(0.00 \%)\end{array}$} & \multirow{2}{*}{$\begin{array}{l}\text { S.aureus } \\
(n=5)\end{array}$} & \multirow{2}{*}{$\begin{array}{c}\text { S.epidermidis } \\
(n=50)\end{array}$} & \multirow{2}{*}{$\begin{array}{c}\begin{array}{c}\text { S.saprophyticus } \\
(n=3)\end{array} \\
1(33.33 \%)\end{array}$} & \multirow{2}{*}{$\begin{array}{c}\begin{array}{c}\text { Str.fecalis } \\
(n=3)\end{array} \\
2(66.67 \%)\end{array}$} \\
\hline Gontamicin & $\mathrm{R}$ & & & & & & \\
\hline Gentamicın & $\mathrm{S}$ & $3(42.85 \%)$ & $1(100 \%)$ & $0(0.00 \%)$ & $34(68 \%)$ & $2(66.67 \%)$ & $1(33.33 \%)$ \\
\hline \multirow{2}{*}{ Tobramycin } & $\mathrm{R}$ & 6 (85.71\%) & $1(100 \%)$ & 2 (40\%) & 26 (52\%) & $2(66.67 \%)$ & $3(100 \%)$ \\
\hline & $S$ & 1 (14.28\%) & $0(0.00 \%)$ & $3(60 \%)$ & $24(48 \%)$ & $1(33.33 \%)$ & $0(0.00 \%)$ \\
\hline \multirow{2}{*}{ Amikacin } & $R$ & 4 (57.14\%) & $0(0.00 \%)$ & $1(20 \%)$ & $15(30 \%)$ & $0(0.00 \%)$ & $3(100 \%)$ \\
\hline & $\mathrm{S}$ & $3(42.85 \%)$ & $1(100 \%)$ & $4(80 \%)$ & $35(70 \%)$ & $3(100 \%)$ & $0(0.00 \%)$ \\
\hline \multirow{2}{*}{ Vancomycin } & $\mathrm{R}$ & - & - & $2(40 \%)$ & 17 (34\%) & $0(0.00 \%)$ & $0(0.00 \%)$ \\
\hline & $\mathrm{S}$ & - & - & $3(60 \%)$ & $33(66 \%)$ & $3(100 \%)$ & 3 (100\%) \\
\hline \multirow{2}{*}{ Ampicillin } & $\mathrm{R}$ & 4 (57.14\%) & $1(100 \%)$ & $3(60 \%)$ & $21(42 \%)$ & $2(66.67 \%)$ & $2(66.67 \%)$ \\
\hline & $\mathrm{S}$ & $3(42.85 \%)$ & $0(0.00 \%)$ & $2(40 \%)$ & $29(58 \%)$ & $1(33.33 \%)$ & $1(33.33 \%)$ \\
\hline \multirow{2}{*}{ Cloxacillin } & $\mathrm{R}$ & - & - & $1(20 \%)$ & $26(52 \%)$ & $0(0.00 \%)$ & $2(66.67 \%)$ \\
\hline & $\mathrm{S}$ & - & - & $4(80 \%)$ & $24(48 \%)$ & $3(100 \%)$ & $1(33.33 \%)$ \\
\hline \multirow{2}{*}{ Ciprofloxacin } & $\mathrm{R}$ & $5(71.42 \%)$ & $0(0.00 \%)$ & $2(40 \%)$ & $17(34 \%)$ & $0(0.00 \%)$ & $2(66.67 \%)$ \\
\hline & $S$ & $2(28.57 \%)$ & $1(100 \%)$ & $3(60 \%)$ & $33(66 \%)$ & $3(100 \%)$ & 1 (33.33\%) \\
\hline
\end{tabular}

Table 4: Multi Drug Resistance Rate

\begin{tabular}{|l|c|c|}
\hline Organisms & Gram positive isolates & Gram negative isolates \\
\hline Number & 40 & 8 \\
\hline Percentage & $65.57 \%$ & $100 \%$ \\
\hline Total & \multicolumn{2}{|c|}{48} \\
\hline
\end{tabular}




\section{Discussion}

The spectrum of organisms that cause neonatal sepsis changes over time and varies from region to region ${ }^{8}$. These organisms have also developed increasing multi-drug resistance over the last two decades $^{9}$. Therefore knowledge of the pattern of bacterial isolates and their antimicrobial susceptibility pattern is useful for prompt treatment of patients. Among 340 samples, 69 (20.3\%) showed positive blood culture. The growth positivity rate differs depending on the sample size and the time period of the study. Similar previous studies from home and abroad have reported the growth positivity varying from $5 \%$ to $70 \%{ }^{10,11,12}$. In our study growth positivity rate was high among male neonates (52.17\%) than female neonates $(47.82 \%)(p>0.05)$.Similar finding were reported from various places ${ }^{12,13,14}$. Male preponderance this could be because of the priority given to male babies for medical care in our society.

In the present study, $72.46 \%$ and $27.53 \%$ neonates presented with EOS and LOS, respectively. Similar results have been reported in Iran (77.5\% vs.22.5\%) and Bangladesh $(70.7 \% \text { vs. } 29.3 \%)^{15}$, but in contrast with reports from Saudi Arabia (39\% vs. $61 \%)^{16}$, Pakistan $\left(42 \%\right.$ vs.58\%) ${ }^{17}$ and Nepal where late onset sepsis is more common ${ }^{13}$. This could be due to referral cases.

Gram Positive Cocci (88.40\%) were predominant isolate followed by Gram negative bacilli (11.60\%). In various other hospitals the organisms isolated differ from time to time. Similar findings were reported in Gaza hospital ${ }^{18}$. Coagulase-negative Staphylococcus was predominant in Taipei hospital ${ }^{19}$. In Johannesburg hospital Gram negative bacilli were isolated more in EOS and Coagulase negative Staphylococcus in $\mathrm{LOS}^{20}$. In New Delhi tertiary Hospital, Klebsiella (33.8\%), Enterobacter (7.5\%), Alcaligenes faecalis (4.9\%), and Escherichia coli (4.6\%) being the common microbes. Staphylococcus aureus (24.4\%), followed by Coagulasenegative staphylococci $(7.9 \%)$, were the major Grampositive isolates ${ }^{21}$. Comparing the neonatal blood culture results in different studies, the common isolates may vary from place to place and institution to institution.

In early onset sepsis, gram positive and gram negative bacteria accounted for $86 \%$ and $14 \%$ respectively $(p>0.05)$. In late onset sepsis, only one isolate was Gram negative and remaining were gram positive bacteria. Comparable findings have been reported in other studies ${ }^{22,23,24}$.
In the present study the predominant organism from EOS and LOS are Coagulase negative staphylococci (CoNS). Studies from different countries report CoNS as the predominant organisms in LOS and among infants with indwelling central venous catheters from intensive care units ${ }^{25}$. Recovery of CoNS from blood of septicemic neonates needs to be reviewed with caution since most of them are regarded as contaminants. CoNS especially Staphylococcus epidermidis are the major normal flora of the skin and they can contaminate blood at the venipuncture site during collection of blood ${ }^{26,27}$.

Classical initial (empiric) treatment of neonatal sepsis consists of a combination of penicillin (Benzylpenicillin, Ampicillin or Cloxacillin) and Aminoglycoside (most commonly Gentamicin) ${ }^{28,29}$. In this study, Amikacin was found most efficient for all the isolates. Vancomycin sensitivity was highest for Gram positive organism and Gentamicin was most effective for Gram negative organisms isolated. Gram-negative bacteria showed high-level resistance to ampicillin. This observation is comparable to that of other researchers ${ }^{7,30,31}$.

Antimicrobial sensitivity patterns differ in studies and at different times. This is due to emergence of resistant strains as a result of indiscriminate use of antibiotic $^{16,31}$. The high resistance rates in this study may be associated with frequent use of antibiotics for both prophylaxis and treatments of neonates in hospital. Multiple drug resistance (resistance to two or more drugs) was observed. In gram negative group, MDR was 8 (100\%) and Gram positive were 40 (65.57\%). Among the Gram positives, MDR was observed among Staphylococcus aureus, Coagulase negative staphylococci and while among the Gram negatives, MDR was observed in Klebsiella spp and Escherichia coli. Emerging multiple drug resistance has also reported in other parts of the world ${ }^{32,33}$.

\section{Conclusion}

The study showed the predominance of Gram positive cocci particularly coagulase negative Staphylococci as the causative agent of Neonatal sepsis. This may be a probable indication of nosocomial infection. The antimicrobial susceptibility pattern showed high occurrence of MDR strains. This suggests that empirical antibiotic therapy should be reviewed based on continuous antibiotic resistance surveillance.

\footnotetext{
Acknowledgements: Nil

Funding: Nil

Conflict of Interest: None

Permission from IRB: Yes
} 


\section{References}

1. Bang AT, Reddy HM, Deshmukh MD, Baitule SB, Bang RA. Neonatal and infant mortality in the ten years (1993 to 2003) of the Gadchiroli field trial: effect of home based neonatal care. J Perinatol. 2005;25:S92-107.

2. Haque KN. Defining common infection in children's and neonates. J Hosp Infect. 2007;65: 110-14.

3. Waseem R, Izhars T S. Qureshi A W. Neonatal sepsis Professional Med J. 2005;12(4):451-6.

4. Vergnano S, Sharland M, Kazembe P, Mwansambo C, Heath PT. Neonatal sepsis: an international perspective. Arch Dis. Child Fetal Neonatal. 2005;90:220-24.

5. Gotoff SP, Eds Behrman RE, Kliegman RM, Arvin AM. Neonatal sepsis and meningitis: In: Nelson Textbook of Pediatrics 15th ed. Philadelphia, WB Saunders Company; 1996:528-37.

6. Cheesbrough M. District laboratory practice in tropical countries. Cambridge university Press; 2000:148

7. Clinical Laboratory and Standards Institute. Performance Standards for antimicrobial susceptibility testing, seventeenth informational supplement. 2007;26(3): M100-S16

8. Movahedian AH, Moniri R, Mosayebi Z. Bacterial culture of neonatal sepsis. Iranian J. Publ. Health. 2006;35:84-89.

9. Maryam W, Laeeq A, Maqbool S. Neonatal sepsis spectrum of antibiotic resistance. Proceeding of 10th Annual National Pediatric Conference. 2001;57

10. Shrestha S, Adhikari N, Shakya D, et al. Bacteriological Profile of Neonatal Blood Cultures at Patan Hospital J Nep Paedtr Soc. 2008;26(1):912.

11. Jain NK, Jain VM, Maheshwari S. Clinical Profile of Neonatal Sepsis. Kathmandu Univ Med J. 2003;1(2):117-20

12. Karki BM, Parija SC. Analysis of blood culture isolates from hospitalized neonates in Nepal. Southeast Asian J Trop Med Public Health 1999;30(3):5464-8

13. Shrestha NJ, Subedi KU, Rai GK. Bacteriological Profile of Neonatal Sepsis: A Hospital Based Study. J Nepal Paedtr Soc 2011;31(1):1-5.

14. Mudey GD, Tankhiwale NS, Mudey A. Clinical Profile and Haematological Indices of Clinically
Diagnosed Early Neonatal Septicaemia: A study Conducted in Teaching Institute Attached to Rural Hospital of Wardha District. Int J Current Res Rev 2011;3(1):4-8

15. Rasul $\mathrm{CH}$, Hassan MA, Habibullah M. Neonatal sepsis and use of antibiotic in tertiary care hospital. Pak J Med Sci. 2007;23:78-81

16. Dawodu A, Al Umran K, Danso K. A case study of neonatal sepsis in very low birth weight infants. $N$ Engl J Med 2002;347:240-47.

17. Aftab R, Iqbal I. Bacteriological agents of neonatal sepsis in NICU at Nishtar Hospital Multan. J Coll Physicians Surg Pak 2006;16:216-19

18. El-Jadba AHE, El-Yazji MS. Neonatal Septicemia in Gaza City Hospitals. Pak J Med Sci 2009; 25(2):22631.

19. Lee NC, Chen SJ, Tang RB, Hwang BT. Neonatal bacteremia in a neonatal intensive care unit: analysis of causative organisms and antimicrobial susceptibility. J Chin Med Assoc 2004;67:15-20

20. Motara F, Ballot DE, Perovic O. Epidemiology of neonatal sepsis at Johannesburg Hospital. South Afr J Epidemol Infect 2005;20(3):90-93

21. Kumhar GD, Ramachandran VG \& Gupta P. Bacteriological analysis of blood culture isolates from neonate in a tertiary care hospital in India. $J$ Health Popul Nutr 2002;20(4): 343-47.

22. Trotman H, Bell Y. Neonatal sepsis in very low birth weight infants at the University Hospital of the West Indies. West Indian Med J 2006;55:165-69.

23. Makhoul IR, Sujov P, Smolkin T, Lusky A, Reichman B. Epidemiological, Clinical and Microbiological Characteristics of Late Onset Sepis Among Very Low Birth Weight Infants in Israel : A National Survey. Pediatrics 2002;109:34-39.

24. Mehr SS, Sadowsky JL, Doyle LW, Carr J. Sepsis in neonatal intensive care in the late 1990s. J Paediatr Child Health 2002;38:246-51.

25. Munson DP, Thompson TR, Johnson DE, Rhame FS, VanDrunen N, Ferrieri P. Coagulasenegative staphylococcal septicemia: experience in a newborn intensive care unit. J Pediatr 1982;101:602-5.

26. Okada Y, Klein NJ, van Saene HK, Webb G, Holzel $\mathrm{H}$, Pierro A. Bactericidal activity against coagulasenegative staphylococci is impaired in infants receiving long-term parenteral nutrition. Ann Surg 2000;231:276-81.

27. Klein MD, Rood K, Graham P. Bacteriology of neonatal sepsis. Pediatr Infect Dis J 1990;9:778. 
28. Kaufman D and Fairchild K D. Clinical Microbiology of Bacterial and Fungal Sepsis in Very-Low-BirthWeight Infants ASM 2004;17(3):638-80

29. Rahman S, Hameed A, Roghani MT, Ullah Z. Multi-drug resistant neonatal sepsis in Peshawar, Pakistan. Arch Dis Child Fetal Neonatal 2002;87:F52-4.

30. Bindayna KM, Jamsheer A, Farid E, et al. Neonatal sepsis 1991-2001: prevalent bacterial agents and antimicrobial susceptibilities in Bahrain. Med Princ Pract 2006;15(2):131-36.
31. Basher Hashemi F, Gharebaghi M. Etiology of neonatal bacterial septicemia and antibiotic sensitivity pattern of isolates (Persian). Med J Tabriz Uni Med Sci 2001;52(1):15-19.

32. Leibovitz $E$, Flidel-Rimon $O$, Juster-Reicher $A$, Amitay M, Miskin A, Barak Y, Mogilner B. Sepsis at a neonatal intensive care unit: a four-year retrospective study (1989- 1992). Isr J Med Sc 1997;33:734-38.

33. Köksal N, Hacimustafaoğlu M, Bağci S, Celebi S. Meropenem in severe infections due to multi resistant gram negative bacteria. Indian J Pediatr 2001;68:15-19. 